\title{
Strategies for measurement of atmospheric column means of carbon dioxide from aircraft using discrete sampling
}

\author{
P. S. Bakwin, ${ }^{1}$ P. P. Tans, ${ }^{1}$ B. B. Stephens, ${ }^{2,3}$ S. C. Wofsy, ${ }^{4}$ C. Gerbig,${ }^{4}$ and A. Grainger ${ }^{5}$ \\ Received 10 December 2002; revised 23 April 2003; accepted 8 May 2003; published 27 August 2003.
}

[1] Automated flask sampling aboard small charter aircraft has been proposed as a lowcost, reliable method to greatly increase the density of measurements of $\mathrm{CO}_{2}$ mixing ratios in continental regions in order to provide data for assessment of global and regional $\mathrm{CO}_{2}$ budgets. We use data from the $\mathrm{CO}_{2}$ Budget and Rectification-Airborne 2000 campaign over North America to study the feasibility of using discrete (flask) sampling to determine column mean $\mathrm{CO}_{2}$ in the lowest $4 \mathrm{~km}$ of the atmosphere. To simulate flask sampling, data were selected from profiles of $\mathrm{CO}_{2}$ measured continuously with an onboard (in situ) analyzer. We find that midday column means can be determined without bias relative to true column means measured by the in situ analyzer to within 0.15 and better than $0.10 \mathrm{ppm}$ by using 10 and 20 instantaneously collected flask samples, respectively. More precise results can be obtained by using a flask sampling strategy that linearly integrates over portions of the air column. Using less than 8-10 flasks can lead to significant sampling bias for some common profile shapes. Sampling prior to the breakup of the nocturnal stable layer will generally lead to large sampling bias because of the inability of aircraft to probe large $\mathrm{CO}_{2}$ gradients that often exist very close to the ground at night and during the early morning. INDEX TERMS: 0365 Atmospheric Composition and Structure: Troposphere-composition and chemistry; 0394 Atmospheric Composition and Structure: Instruments and techniques; KEYWORDS: carbon dioxide, column mean, column integral, COBRA, flask sampling

Citation: Bakwin, P. S., P. P. Tans, B. B. Stephens, S. C. Wofsy, C. Gerbig, and A. Grainger, Strategies for measurement of atmospheric column means of carbon dioxide from aircraft using discrete sampling, J. Geophys. Res., 108(D16), 4514, doi:10.1029/2002JD003306, 2003.

\section{Introduction}

[2] Low-cost, reliable methods are needed to obtain regular measurements of $\mathrm{CO}_{2}$ mixing ratio in the lower atmosphere over the continents [Wofsy and Harriss, 2002]. A method suggested by Tans et al. [1996] is the use of automated flask sampling aboard small charter aircraft, allowing samples to be collected without the presence of a scientist. The National Oceanic and Atmospheric Administration (NOAA) Climate Monitoring and Diagnostics Laboratory (CMDL) has carried out a program of this type since 1992 at a site in northern Colorado, United States, and for shorter periods at several other sites around the globe. Added advantages of flask sampling over in situ instrumentation are that many trace gas mixing ratios and isotope

\footnotetext{
${ }^{1}$ National Oceanic and Atmospheric Administration, Climate Monitoring and Diagnostics Laboratory, Boulder, Colorado, USA.

${ }^{2}$ Cooperative Institute for Research in Environmental Sciences, University of Colorado, Boulder, Colorado, USA.

${ }^{3}$ Now at Research Aviation Facility, Atmospheric Technology Division, National Center for Atmospheric Research, Boulder, Colorado, USA.

${ }^{4}$ Department of Earth and Planetary Sciences, Harvard University, Cambridge, Massachusetts, USA.

${ }^{5}$ Department of Atmospheric Sciences, University of North Dakota, Grand Forks, North Dakota, USA.
}

Copyright 2003 by the American Geophysical Union. 0148-0227/03/2002JD003306\$09.00 ratios can be measured in the flask air, and analyses from a global network of sites can be carried out on a single set of laboratory instruments, alleviating possible problems of intercomparability.

[3] Measurements of the column mean of $\mathrm{CO}_{2}$ through the lower atmosphere could provide a strong constraint for inverse models of the global $\mathrm{CO}_{2}$ budget. Inverse methods use global circulation models (GCMs) to simulate atmospheric transport in order to calculate $\mathrm{CO}_{2}$ sources and sinks from spatial gradients of $\mathrm{CO}_{2}$ mixing ratios. Imperfect representation of atmospheric mixing, especially in the vertical, makes problematic the use of mixing ratio data obtained at the surface or at any discrete altitude. In particular, many GCMs currently have poor representation of the planetary boundary layer, which often has large vertical gradients of $\mathrm{CO}_{2}$. Column data will also be needed to calibrate $\mathrm{CO}_{2}$ data obtained from future satellite-based sensors. Measurements of the stable isotopic composition of $\mathrm{CO}_{2}\left({ }^{13} \mathrm{C} /{ }^{12} \mathrm{C}\right.$ and $\left.{ }^{18} \mathrm{O} /{ }^{16} \mathrm{O}\right)$ provide additional information enabling the partition of $\mathrm{CO}_{2}$ sources and sinks into component processes such as ocean versus land net fluxes [Ciais et al., 1995], $\mathrm{C}_{3}$ versus $\mathrm{C}_{4}$ photosynthesis [Farquhar et al., 1989; Fung et al., 1997], and photosynthesis versus respiration [Francey and Tans, 1987; Peylin et al., 1999].

[4] The column mean $\mathrm{CO}_{2}$ could be very precisely determined (i.e., to within instrument precision) using linearly integrated flask samples that cover the entire 

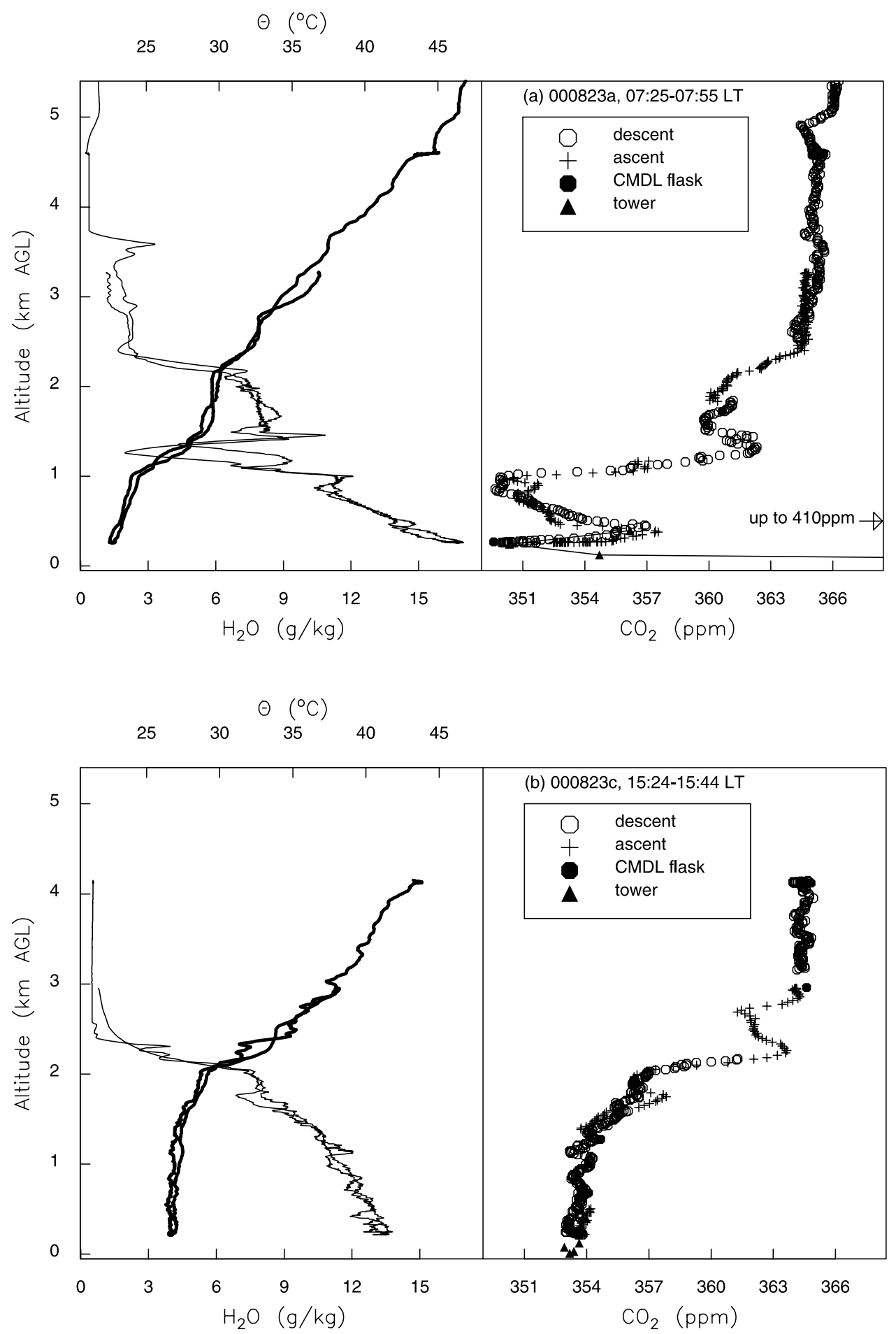

Figure 1. Profiles of $\mathrm{CO}_{2}, \mathrm{H}_{2} \mathrm{O}$ and potential temperature $(\Theta)$ above and at the Park Falls, Wisconsin, tower, during 23-24 August 2000: (a) morning profile on 23 August, (b) afternoon profile on 23 August, (c) morning profile on 24 August, (d) midday profile on 24 August, and (e) afternoon profile on 24 August. Times are given in Local Time (LT).

profile. An additional benefit of integrated flask sampling is that small-scale atmospheric variability in the horizontal and vertical dimensions will be averaged out, providing a data set that may be well suited for use in transport models that have coarse spatial resolution. Key disadvantages of integrated sampling are that correlations between trace gases are smeared out, reducing the utility of the data for determining source signatures, and features of the atmospheric structure, such as the boundary layer top, cannot be accurately identified. Also, collecting air into flasks with linear weighting in time can be difficult, and most flask sampling systems introduce a weighting function that depends on 

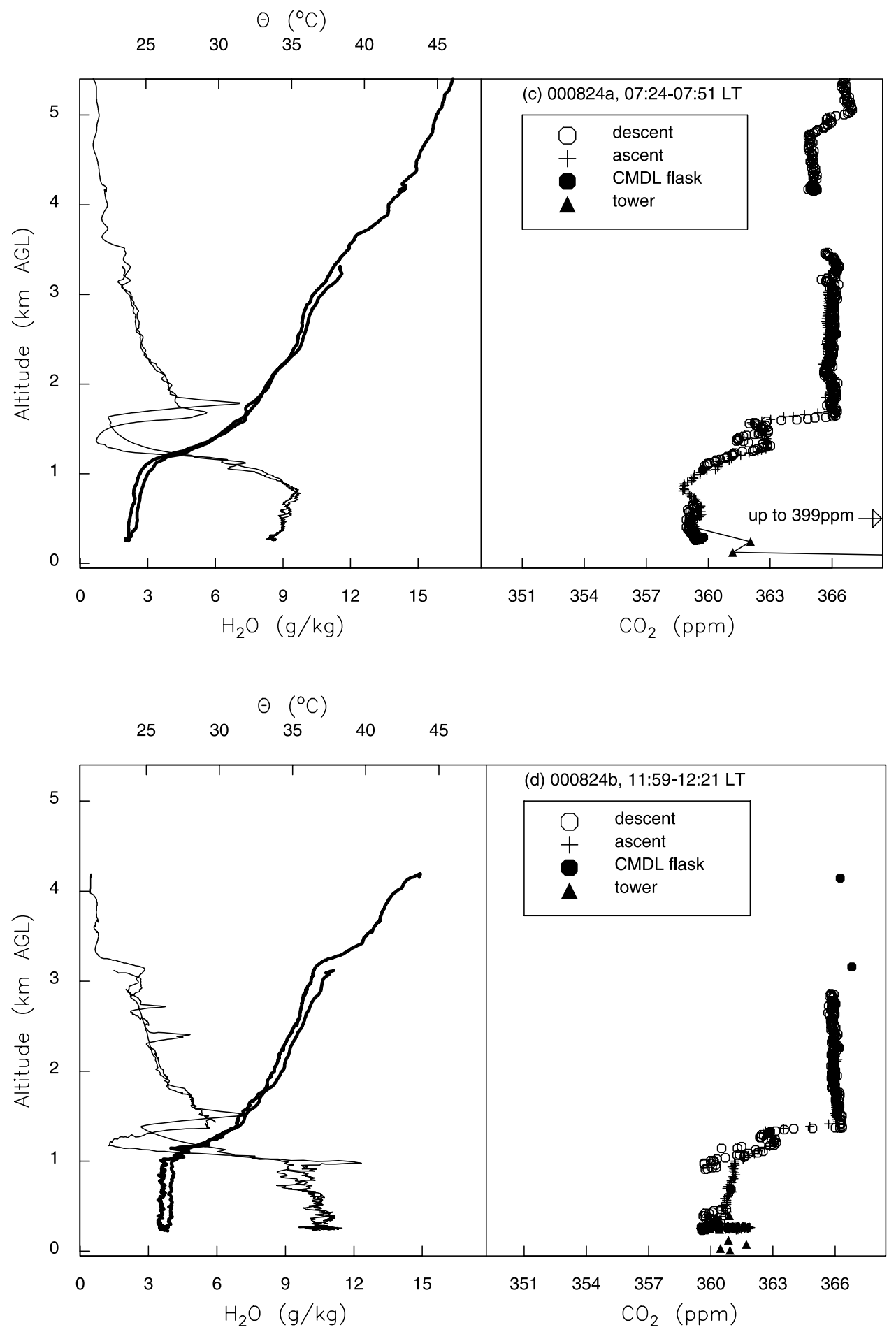

Figure 1. (continued)

system characteristics. Atmospheric Observing Systems (Niwot, Colorado), in collaboration with CMDL, has developed a simple system for collecting linearly integrated flask samples which is being tested for use aboard aircraft (J. Smith, personal communication, 2002).

[5] The extensive continuous in situ $\mathrm{CO}_{2}$ measurements obtained during the $\mathrm{CO}_{2}$ Budget and Rectification Airborne 2000 (COBRA-2000) campaign over the United States and Canada provide a useful data set to test strategies for defining column means using flask sampling. In this paper we use the COBRA-2000 data to determine the precision to which column mean $\mathrm{CO}_{2}$ can be determined using various flask sampling approaches.

\section{Methods}

[6] The COBRA-2000 campaign used instruments aboard the University of North Dakota (UND) Cessna 


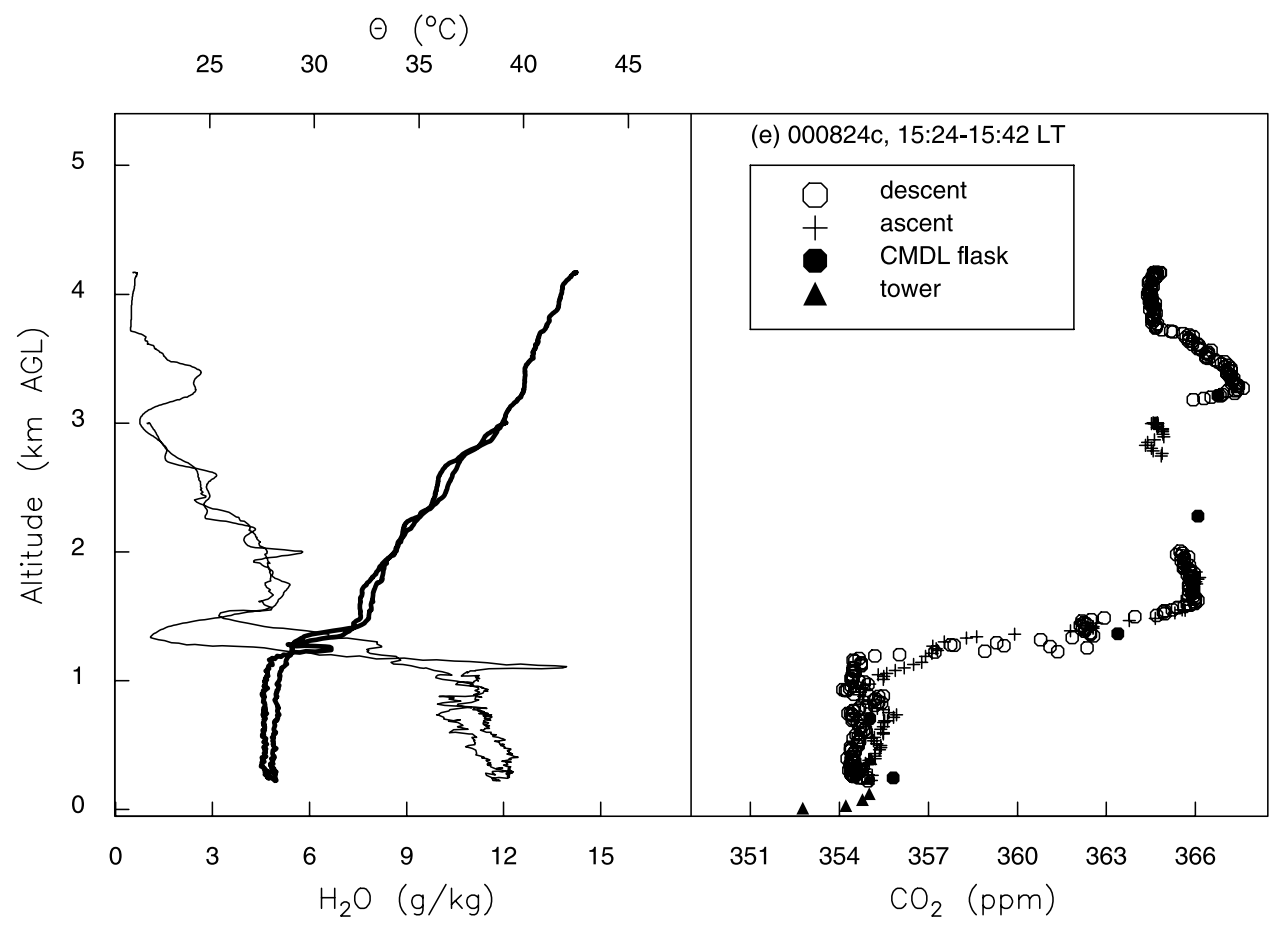

Figure 1. (continued)

Citation jet airplane to measure trace gas mixing ratios over North America during 28 July to 24 August 2000. Molar mixing ratios of $\mathrm{CO}_{2}$ and $\mathrm{CO}$ were measured continuously on board the airplane by the group from Harvard University (C. Gerbig et al., Toward constraining regional-scale fluxes of $\mathrm{CO}_{2}$ with atmospheric observations over a continent: 1 . Observed spatial variability, submitted to Journal of Geophysical Research, 2003, hereinafter referred to as Gerbig et al., submitted manuscript, 2003), and flask samples were obtained for measurements at NOAA/CMDL of $\mathrm{CO}_{2}, \mathrm{CH}_{4}, \mathrm{CO}, \mathrm{H}_{2}, \mathrm{~N}_{2} \mathrm{O}$ and $\mathrm{SF}_{6}$, and at the University of Colorado Institute for Arctic and Alpine Research (CU/ INSTAAR) of $\delta^{13} \mathrm{C}$ and $\delta^{18} \mathrm{O}$ in $\mathrm{CO}_{2}$. The flask samples allowed us to (1) measure several trace gases in order to give information about air mass history, (2) determine the isotopic signatures of $\mathrm{CO}_{2}$ sources and sinks, and (3) ensure that the in situ data were comparable to the WMO scales for $\mathrm{CO}_{2}$ and CO, which are maintained by CMDL [Zhao et al., 1997; Novelli et al., 1991]. Additional flask samples were collected for $\mathrm{O}_{2} / \mathrm{N}_{2}$ analysis at Scripps and were also analyzed at CMDL. Continuous measurements of water vapor and air temperature were made by the UND group.

[7] Flight patterns during COBRA-2000 were chosen to fulfill a variety of mission objectives, including boundary layer budget studies, Lagrangian budget studies, and regional surveys. In addition there were several transit flights. Ninety-six fairly complete continuous $\mathrm{CO}_{2}$ vertical profiles were obtained during the campaign. At times two or more profiles were flown in close proximity, such that the trace gas profiles were not completely independent. Nevertheless, in this analysis we treat each of the profiles as independent. All parameters measured aboard the aircraft were recorded at 1-s intervals, typically corresponding to an altitude increment of about $6 \mathrm{~m}$. Generally, $\mathrm{CO}_{2}$ data were recorded at $4 \mathrm{~Hz}$ and processed into median filtered
$0.5 \mathrm{~Hz}$ data [Daube et al., 2002]. Gaps in the $\mathrm{CO}_{2}$ profiles correspond to calibrations, which typically took about $90 \mathrm{~s}$. The precision of the Harvard $\mathrm{CO}_{2}$ instrument was $0.25 \mathrm{ppm}$ (Gerbig et al., submitted manuscript, 2003).

[8] On 23-24 August 2000, five flights were made over the Park Falls, Wisconsin, 447-m-tall tower site that has been operated by NOAA/CMDL since 1994. The landscape around the tower is quite flat and heavily forested. At the tower we measured $\mathrm{CO}_{2}$ mixing ratios at $11,30,76,122$, 244 and $396 \mathrm{~m}$ above the ground, with one measurement at each level about every $12 \mathrm{~min}$ [Bakwin et al., 1998]. We also measured wind speed and direction, temperature, humidity and surface pressure, as well as the atmosphere/ surface exchange of $\mathrm{CO}_{2}, \mathrm{H}_{2} \mathrm{O}$, heat and momentum [Berger et al., 2001; Davis et al., 2003]. Two profiles were obtained over the tower during each flight as the airplane descended in a spiral pattern, and then ascended while leaving the vicinity of the tower (Figure 1). Below $3 \mathrm{~km}$ above ground level (AGL) during the descents the average horizontal distance between the airplane and the tower was about $3 \mathrm{~km}$.

[9] In order to obtain complete profiles between 0.25 and $4 \mathrm{~km}$ AGL for calculation of column means we filled the profiles by linear interpolation of the $\mathrm{CO}_{2}$ data to $6 \mathrm{~m}$ intervals. Surface elevation was determined using a digital elevation model. For profiles when the aircraft did not reach $4 \mathrm{~km}$ we assumed a uniform profile above the highest measured altitude, which is consistent with data collected above about $3 \mathrm{~km}$. To simulate the effect of instrument noise and small-scale ambient variability, random, normally distributed (standard deviation $=0.2 \mathrm{ppm}$ (Gerbig et al., submitted manuscript, 2003)) noise was added to the interpolated data. Subsequently, we refer to these as filled profiles. For most of the profiles we neglected variations of $\mathrm{CO}_{2}$ below $0.25 \mathrm{~km}$ AGL. Most aircraft will not fly much 
Table 1. Density-Weighted Column Averages of $\mathrm{CO}_{2}$ Mole Fraction From the Surface to $4 \mathrm{~km}$ AGL Calculated From Aircraft, Tower, and Simulated Flask Sample Data During COBRA-2000 Flights Over the Wisconsin Tower, 23-24 August 2000

\begin{tabular}{ccccc}
\hline $\begin{array}{c}\text { Profile Number } \\
0.25-4 \mathrm{~km}\end{array}$ & $\begin{array}{c}\text { Aircraft }+ \\
\text { Tower, ppm }\end{array}$ & $\begin{array}{c}\text { Aircraft Only } \\
0-4 \mathrm{~km}, \mathrm{ppm}\end{array}$ & $\begin{array}{c}\text { Aircraft Only } \\
0-4 \mathrm{~km}, \mathrm{ppm}\end{array}$ & $\begin{array}{c}\text { 20 Flasks } \\
0.25-4 \mathrm{~km}, \mathrm{ppm}\end{array}$ \\
\hline $823 \mathrm{a} 1$ & 361.41 & 360.15 & 360.89 & 360.82 \\
$823 \mathrm{a} 2$ & 360.63 & 359.44 & 360.06 & 359.96 \\
$823 \mathrm{c} 1$ & 358.67 & 358.70 & 359.07 & 359.11 \\
$823 \mathrm{c} 2$ & 358.39 & 358.42 & 358.76 & 358.79 \\
$824 \mathrm{a} 1$ & 364.39 & 363.59 & 363.91 & 364.01 \\
$824 \mathrm{a} 2$ & 364.20 & 363.40 & 363.69 & 363.62 \\
$824 \mathrm{~b} 1$ & 364.24 & 364.18 & 364.52 & 364.47 \\
$824 \mathrm{~b} 2$ & 364.22 & 364.20 & 364.47 & 364.42 \\
$824 \mathrm{c} 1$ & 362.38 & 362.09 & 362.63 & 362.50 \\
$824 \mathrm{c} 2$ & 361.75 & 361.47 & 361.94 & 361.96 \\
\hline
\end{tabular}

${ }^{\text {a} P r o f i l e s ~ a r e ~ s h o w n ~ i n ~ F i g u r e ~ 1, ~ w h e r e ~ t i m e s ~ a r e ~ l i s t e d . ~}$

${ }^{\mathrm{b}}$ Aircraft only $(0-4 \mathrm{~km})$ assumes constant $\mathrm{CO}_{2}$ below the lowest altitude sampled by the aircraft.

lower than this except during take off and landing. The influence of near-surface gradients of $\mathrm{CO}_{2}$ on the column means was examined using combined data from the airplane and the Wisconsin tower obtained on 23 and 24 August.

[10] Discrete flask sampling was simulated by selecting values from the filled profiles. Up to 20 flasks were sampled from the data either instantaneously or by averaging over $90 \mathrm{~m}$ intervals in height to simulate a finite time period for flask collection (equal to approximately $15 \mathrm{~s}$ ). Samples were selected uniformly with height from 0.25 to $4 \mathrm{~km}$ AGL. Density-weighted $\mathrm{CO}_{2}$ column means were compared to those calculated from the original filled profiles. Real flask samples were obtained during most of the profiles, but with typically four or fewer samples collected below $4 \mathrm{~km}$ AGL during each profile it is impractical to compute column means from the real flask samples for comparison with the in situ data.

[11] Some sources of uncertainty were estimated by Monte Carlo methods. Uncertainty due to instrument noise was estimate by selecting samples from repeatedly interpolated profiles, and was generally about 0.05 ppm (1 standard deviation) for the column mean using 6-20 discrete samples. This corresponds to uncertainty due to the random error that was added to the interpolated segments of the profiles, and should be similar to the uncertainty of the column mean due to instrument noise. Uncertainty due to small-scale ambient variability of $\mathrm{CO}_{2}$ was estimated by randomly varying the sampling altitudes by up to $\pm 60 \mathrm{~m}$ from the nominal values. An uncertainty in the column mean of about $0.1 \mathrm{ppm}$ was obtained from the combination of these two factors, similar to the uncertainty of $0.19 \mathrm{ppm}$ for the same data set determined by Gerbig et al. (submitted manuscript, 2003) by using an autocovariance method.

\section{Results}

[12] The COBRA-2000 profiles were obtained during generally fair weather conditions in mid to late summer over biologically productive areas (Gerbig et al., submitted manuscript, 2003). Of the 96 aircraft profiles we examined all but 11 had lower $\mathrm{CO}_{2}$ in the lowest $1 \mathrm{~km}$ than above $3 \mathrm{~km}$. Profiles obtained over the Wisconsin tower provide typical examples (Figure 1). A rapid change in $\mathrm{CO}_{2}$ with height at around $1-2 \mathrm{~km}$ AGL was usually observed, reflecting the top of the daytime convective boundary layer (CBL) [Yi et al., 2001]. Depletion of $\mathrm{CO}_{2}$ in the $\mathrm{CBL}$ is due to net sequestration by the vegetation and soils at this time of year [Davis et al., 2003]. Above the CBL, $\mathrm{CO}_{2}$ mixing ratios tended to be fairly uniform with height. During the afternoon of 24 August (Figure 1e), as during some other profiles, layers of high $\mathrm{CO}_{2}$ were observed above $3000 \mathrm{~m}$ and have been attributed to distant biomass fires (Gerbig et al., submitted manuscript, 2003).

[13] Early morning profiles at the Wisconsin tower (Figures 1a and 1c) are characterized by very high $\mathrm{CO}_{2}$ mixing ratios close to the ground, which result from nighttime buildup within the shallow, stable nocturnal boundary layer (NBL) of $\mathrm{CO}_{2}$ from respiration [Bakwin et al., 1995, 1998]. The layer of high $\mathrm{CO}_{2}$ is well below the altitudes accessed by the airplane, and is observed in the tower data only. The $\mathrm{CO}_{2}$ mixing ratio at $11 \mathrm{~m}$ above the ground (below the treetops) during the morning flight on 23 August was $410 \mathrm{ppm}$ (Figure 1a). For the morning profiles, using only the aircraft data, and assuming that $\mathrm{CO}_{2}$ is constant below the lowest altitude reached by the airplane, would result in an underestimate of the column mean from the surface to $4 \mathrm{~km}$ of about $1 \mathrm{ppm}$ (Table 1 ). The buildup of $\mathrm{CO}_{2}$ in the NBL is highly nonuniform in space and time. Therefore representative column means will be difficult to obtain from aircraft during the early morning hours, particularly if tower data are not available.

[14] Discrete sampling may not adequately capture the rapid change in $\mathrm{CO}_{2}$ at the $\mathrm{CBL}$ top, adding uncertainty (noise) to the column means computed from the discrete samples (Figure 2). Profiles sampled with 4 and 6 flasks overestimated the in situ column $(0.25-4 \mathrm{~km})$ averages by about 0.2 and $0.1 \mathrm{ppm}$, respectively. Since most of the profiles had roughly similar shapes (see Figure 1) this represents a true bias, that is, a consistent overestimate. With 10 or more samples, flask profile means were not significantly different from the nominal values (at the 95\% level), and the uncertainty (1 standard deviation) of the mean was $0.15 \mathrm{ppm}$ or less. Using a sampling strategy in which each flask linearly integrates over a $90 \mathrm{~m}$ layer did not significantly reduce the overestimate for profiles sampled by a small number of flasks but did reduce the uncertainty approximately in accord with the proportion of the total profile that was captured by the flasks; that is, with 


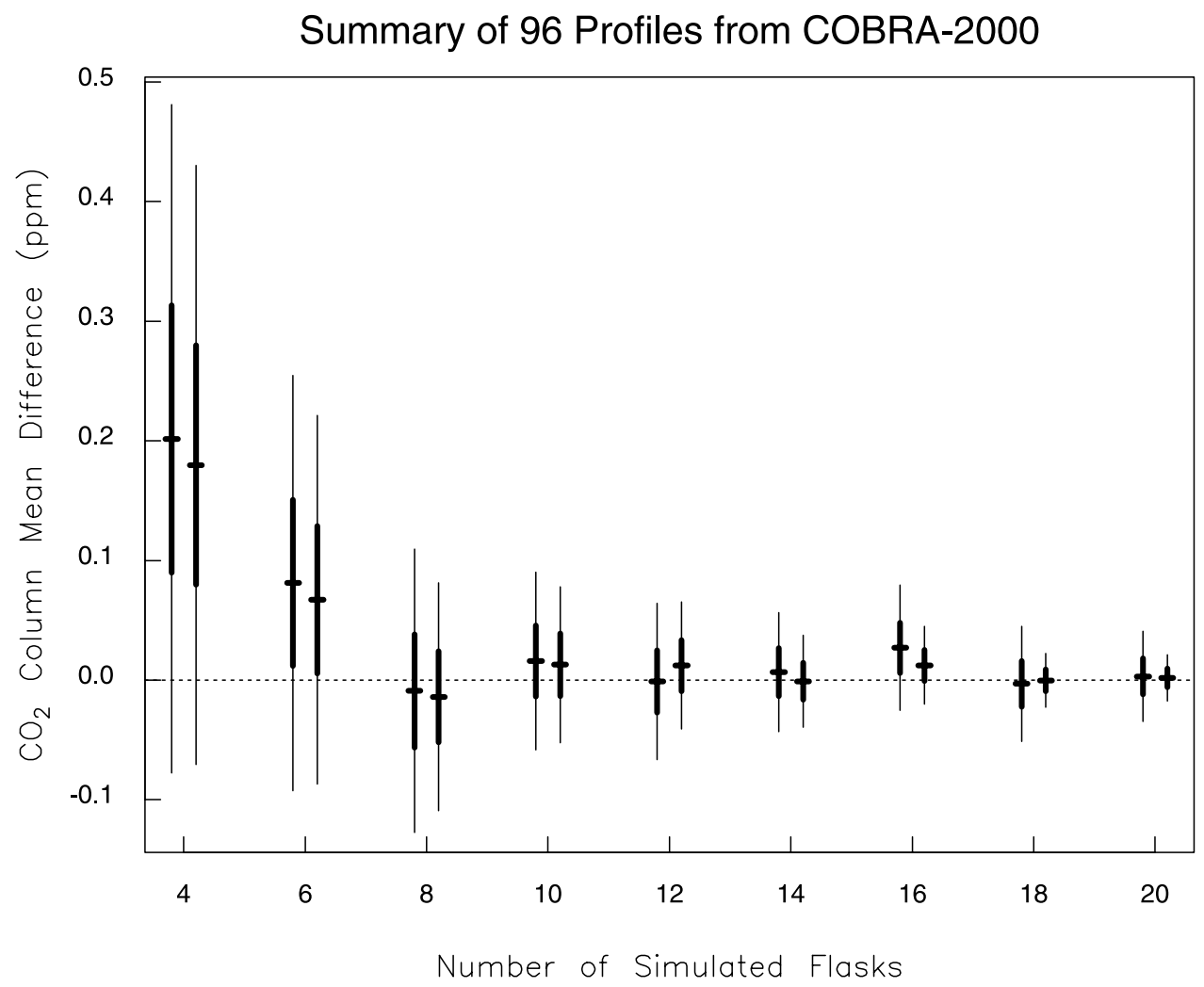

Figure 2. Statistical summary of column mean $\mathrm{CO}_{2}$ calculated from simulated flask samples minus column mean $\mathrm{CO}_{2}$ calculated from in situ aircraft data for 96 interpolated profiles $(0.25-4 \mathrm{~km}$ AGL) obtained during COBRA-2000. Symbols slightly to the left of each number of flask value are data from individual profiles with flasks obtained instantaneously, and symbols slightly to the right are data using flasks that linearly integrate over $90 \mathrm{~m}$ increments in height. Horizontal lines are mean values, thick vertical lines indicate $95 \%$ confidence intervals of the mean, and the full length of the thin vertical lines is equal to one standard deviation of the mean.

20 samples almost one half of the $0.25-4 \mathrm{~km}$ column was sampled and the reduction of uncertainty was close to $50 \%$. Integrating over larger vertical distances would obviously reduce the uncertainty further.

[15] Continuous profiles of water vapor, potential temperature $(\Theta)$ or other tracers could be used to identify the CBL top in order to improve the estimate of the column mean from discrete samples. Water vapor and $\Theta$ data for the profiles over the Wisconsin tower are shown in Figure 1. A distinct relic boundary layer is evident above the NBL in the morning profiles for 23 and 24 August (Figures 1a, 1c, and 1d). The vertical distributions of $\mathrm{CO}_{2}$ and $\mathrm{H}_{2} \mathrm{O}$ show considerable structure within the relic layer. The top of the relic layer can be accurately estimated as the point above which the variance of the $\mathrm{H}_{2} \mathrm{O}$ (or $\mathrm{CO}_{2}$ ) mixing ratio decreases markedly. These relic layers, which were about 2.4 and $1.5 \mathrm{~km}$ deep on 23 and 24 August, respectively, persisted throughout the day. As the day progresses the $\mathrm{CBL}$ grows into the relic layer. The top of the CBL can be identified as the point where $\Theta$ begins to increase rapidly with height. The CBL grew to about 2.0 and $1.2 \mathrm{~km}$ on 23 and 24 August, respectively (Figures $1 \mathrm{~b}$ and 1e). A large gradient in $\mathrm{CO}_{2}$ exists between the top of the CBL and the top of the relic layer. With such complex atmospheric structure we have been unsuccessful in deriving a simple strategy to use $\Theta$ and $\mathrm{H}_{2} \mathrm{O}$ measurements to improve estimates of the column means from discrete sampling.

\section{Discussion and Conclusions}

[16] We determined the column mean for $\mathrm{CO}_{2}$ in a layer of the atmosphere up to $4 \mathrm{~km}$ above the ground using discrete sampling from continuous aircraft profiles to simulate flask sampling. We find that 10 and 20 instantaneously collected flasks can define the column mean without measurable bias to typically within about 0.15 and better than $0.10 \mathrm{ppm}$, respectively. More precise results can be obtained by using a flask sampling strategy that linearly integrates over portions of the air column. Using fewer than 8-10 flasks can lead to significant (at the 95\% level) sampling bias for some typical profile shapes (Figure 2).

[17] The COBRA-2000 profiles were obtained mainly over productive continental regions during the growing season. Most of the profiles showed substantial depletion of $\mathrm{CO}_{2}$ in the $\mathrm{CBL}$ because of uptake by the vegetation (e.g., Figure 1). In winter in these areas, $\mathrm{CO}_{2}$ is likely to be higher in the CBL than aloft because of a net surface source from respiration and fossil fuel combustion. Higher $\mathrm{CO}_{2}$ in the CBL than aloft over Harvard Forest, Massachusetts, in winter is commonly observed in profiles that CMDL has obtained regularly since 1999 using an automated flask 
sampling system (NOAA/CMDL, unpublished data). When such profiles are sampled with a small number of flasks (i.e., less than 8-10) we would expect similar sampling bias, but of opposite sign, to that observed for the COBRA profiles. Over other areas where net surface fluxes are small, such as the oceans or desert regions, vertical profiles are likely to be more uniform and hence more easily characterized by discrete flask sampling.

[18] Aircraft sampling cannot capture strong gradients in $\mathrm{CO}_{2}$ that often exist very close to the ground during the nighttime and early morning. Tower data show large build up of $\mathrm{CO}_{2}$ below the nocturnal near-surface inversion, which is typically less than $200 \mathrm{~m}$ deep, and often less than $100 \mathrm{~m}$. Usually by about 10:00 local time these gradients are dissipated by convective mixing [Bakwin et al., 1998]. Aircraft profiles that do not penetrate this layer underestimate the column mean below $4 \mathrm{~km}$ by about $1 \mathrm{ppm}$.

[19] Sources of uncertainty include instrument noise and small-scale atmospheric variability. We investigated these by using Monte-Carlo methods, and found that together they contribute about $0.1 \mathrm{ppm}$ to the uncertainty in the column mean for our profiles. Differences between profiles obtained close in space and time were generally larger, averaging about $0.8 \mathrm{ppm}$ for mixed layer means obtained $100 \mathrm{~km}$ apart (Gerbig et al., submitted manuscript, 2003). Frequent profiling using inexpensive methods such as automated flask sampling can provide a statistical representation of this large ambient variability.

[20] Acknowledgments. COBRA was funded by NSF (ATM9821044), DOE (DE-FG02-98ER62695), NASA (NAG5-7950), and NOAA (NA06GP0406). Carbon dioxide mixing ratio measurements, and site infrastructure and maintenance at the Wisconsin tower were supported by the Atmospheric Chemistry Project of the Climate and Global Change Program of the National Oceanic and Atmospheric Administration, and work at the tower would not be possible without the gracious cooperation of the Wisconsin Educational Communications Board and R. Strand, chief engineer for WLEF-TV.

\section{References}

Bakwin, P. S., C. Zhao, W. Ussler III, P. P. Tans, and E. Quesnell, Measurements of carbon dioxide on a very tall tower, Tellus, Ser. B., 47, 535549, 1995.

Bakwin, P. S., P. P. Tans, D. F. Hurst, and C. Zhao, Measurements of carbon dioxide on very tall towers: Results of the NOAA/CMDL program, Tellus, Ser. B., 50, 401-415, 1998.
Berger, B. W., K. J. Davis, P. S. Bakwin, C. Yi, and C. Zhao, Long-term carbon dioxide fluxes from a very tall tower in a northern forest: flux measurement methodology, J. Oceanic Atmos. Technol., 18, 529-542, 2001.

Ciais, P., P. P. Tans, J. W. C. White, M. Trolier, R. J. Francey, J. A. Berry, D. A. Randall, P. J. Sellers, J. G. Collatz, and D. S. Schimel, Partitioning of ocean and land uptake of $\mathrm{CO}_{2}$ as inferred by $\delta^{13} \mathrm{C}$ measurements from the NOAA Climate Monitoring and Diagnostics Laboratory global air sampling network, J. Geophys. Res., 100, 5051-5070, 1995.

Daube, B. C., K. A. Boering, A. E. Andrews, and S. C. Wofsy, A highprecision fast-response airborne $\mathrm{CO}_{2}$ analyzer for in situ sampling from the surface to the middle stratosphere, J. Atmos. Oceanic Technol., 19, $1532-1543,2002$.

Davis, K. J., P. S. Bakwin, B. W. Berger, C. Yi, C. Zhao, R. Teclaw, and $\mathrm{J}$. Isebrands, The annual cycle of net $\mathrm{CO}_{2}$ exchange over a northern mixed forest as observed from a very tall tower, Global Change Biol., in press, 2003.

Farquhar, G. D., J. R. Ehleringer, and J. A. Berry, Carbon isotope discrimination and photosynthesis, Annu. Rev. Plant Physiol. Plant Mol. Biol., 40, 503-537, 1989.

Francey, R. J., and P. P. Tans, Latitudinal variation in oxygen-18 of atmospheric $\mathrm{CO}_{2}$, Nature, 327, 495-497, 1987.

Fung, I., et al., Carbon 13 exchanges between the atmosphere and biosphere, Global Biogeochem. Cycles, 11, 507-533, 1997.

Novelli, P. C., J. W. Elkins, and P. L. Steele, The development and evaluation of a gravimetric reference scale for measurements of atmospheric carbon monoxide, J. Geophys. Res., 96, 13,109-13,122, 1991.

Peylin, P., P. Ciais, A. S. Denning, P. P. Tans, J. A. Berry, and J. W. C. White, A 3-dimensional study of $\delta^{18} \mathrm{O}$ in atmospheric $\mathrm{CO}_{2}$ : Contribution of different land ecosystems, Tellus, Ser. B, 51, 642-667, 1999.

Tans, P. P., P. S. Bakwin, and D. W. Guenther, A feasible global carbon cycle observing system: A plan to decipher today's carbon cycle based on observations, Global Change Biol., 2, 309-318, 1996.

Wofsy, S. C., and R. C. Harriss, The North American Carbon Program (NACP), report, 75 pp., Interagency Working Group of the U.S. Global Change Res. Prog., Washington, D. C., 2002.

Yi, C., K. J. Davis, B. W. Berger, and P. S. Bakwin, Long-term observations of the dynamics of the continental planetary boundary layer, J. Atmos. Sci., 10, 1288-1299, 2001.

Zhao, C. L., P. P. Tans, and K. W. Thoning, A high precision manometric system for absolute calibrations of $\mathrm{CO}_{2}$ in dry air, J. Geophys. Res., 102, 5885-5894, 1997.

P. S. Bakwin and P. P. Tans, National Oceanic and Atmospheric Administration, Climate Monitoring and Diagnostics Laboratory, Boulder, CO 80305, USA. (pbakwin@cmdl.noaa.gov)

C. Gerbig and S. C. Wofsy, Department of Earth and Planetary Sciences, Harvard University, Cambridge, MA 02138, USA.

A. Grainger, Department of Atmospheric Sciences, University of North Dakota, Grand Forks, ND 58202, USA.

B. B. Stephens, Research Aviation Facility, Atmospheric Technology Division, National Center for Atmospheric Research, Boulder, CO 80307, USA. 